\title{
Prevalence, Detection and Identification of Listeria monocytogenes in Retail Chicken Meat in Ludhiana, India by Employing conventional Isolation Techniques and Molecular Polymerase Chain Reaction (PCR) Assay
}

\author{
Nishchal Dutta $^{1 *}$, H. S. Banga ${ }^{2}$, Sidhartha Deshmukh ${ }^{2}$ and Geeta Devi Leishangthem ${ }^{2}$ \\ ${ }^{1}$ Department of Veterinary Pathology, Khalsa College of Veterinary and Animal Sciences, \\ Amritsar-143002, Punjab, India \\ ${ }^{2}$ Department of Veterinary Pathology, College of Veterinary Science Guru Angad Dev \\ Veterinary and Animal Sciences University, Ludhiana-141004, Punjab, India \\ *Corresponding author
}

\author{
A B S T R A C T
}

\begin{tabular}{|c|}
\hline Keywords \\
\hline $\begin{array}{l}\text { L. monocytogenes, } \\
\text { chicken meat, } \\
\text { PALCAM selective } \\
\text { agar, BHI } \\
\text { brothandPCR }\end{array}$ \\
\hline Article Info \\
\hline $\begin{array}{l}\text { Accepted: } \\
\text { 14 June } 2020 \\
\text { Available Online: } \\
10 \text { July } 2020\end{array}$ \\
\hline
\end{tabular}

\section{Introduction}

The genus Listeria includes Gram-positive, non-spore forming, catalase-positive rodshaped bacteria, which were once classified into the family Corynebacteriaceae. Listeria species appear as small rods ranging in size from 0.4 to 0.5 by $1-2 \mu \mathrm{m}$ and sometimes are
Listeria monocytogenes is one of the major food contaminants with potential to cause lethal food poisoning in both humans and animals. Among different food borne pathogens, Listeria monocytogenes has a high mortality rate and is therefore considered one of the most dangerous foodborne pathogen. The present study was aimed at finding the prevalence of Listeria monocytogenes in raw chicken meat purchased from different retail outlets and local butcher shops across the Ludhiana city. In the present study a total of 100 raw chicken meat samples were collected ( 80 fresh raw samples and 20 frozen chicken meat products). During this study, 100 chicken meat samples were inoculated in PALCAM selective agar for the selective isolation of L. monocytogenes and were later characterized by a combination of microscopic and biochemicaltests. Results of the study revealed that02 samples were containing L. monocytogenes, which is $02 \%$ of the total samples. These positive samples were subjected to molecular characterization using standard PCR technique to attest their presence in these meat samples. The PCR technique was found to be more specific/sensitive, reliable, precise and rapid technique to supplement the conventional methods of diagnosis of the L. monocytogenes. 
0.83 ) and salt concentrations (up to $10 \%$ ) as well. Listeria spp. is aerobic, microaerophilic and facultatively anaerobic and can be cultured over a wide temperature range. The organism has a growth temperature range of approximately $1^{\circ} \mathrm{C}-45^{\circ} \mathrm{C}$, making it a psychrotroph and a mesophile. There are, however, temperature-dependent growth factors.

The peritrichous flagella are formed at 20$25^{\circ} \mathrm{C}$ and cause the organism to be motile, whereas at $37^{\circ} \mathrm{C}$ the organism is weak or nonmotile. Additionally, its ability to not only survive but to grow as a psychrotroph at $4{ }^{\circ} \mathrm{C}$ makes this pathogen unique from other commonly found food-borne pathogens which are usually inhibited from growth at refrigeration temperatures. A coccoid appearance may be seen in direct smears. Listeria spp. produces flagella at room temperature and exhibits a tumbling motion when examined in broth and swarming motility can be observed in semi-soft agar at $30^{\circ} \mathrm{C}$. The wide distribution of $L$. monocytogenes in nature allows this bacterium to be easily spread and cause infection. Listeria monocytogenes can cause infection by several transmission routes such as ingestion of contaminated foods (e.g. unpasteurized milk or contaminated ready-toeat foods). Many foods such as soft cheeses, hot dogs, and seafood have been implicated in listeriosis outbreaks, but L. monocytogenes also can be isolated from other foods such as beef, pork, fermented sausages, fresh produce, and fish products.

\section{Materials and Methods}

The predominant analysis of laboratory work was done at the Department of Veterinary Pathology, College of Veterinary Science, Guru Angad Dev Veterinary and Animal Sciences University (GADVASU), Ludhiana, from the meat samples collected.

\section{Collection and processing of Samples}

A total of 100 samples of poultry meat (80 raw chicken meat and 20 frozen meat) samples were collected from different retail shops in the vicinity of Ludhiana. About 100 grams of meat samples (muscle, liver, gizzard, kidney and heart) were collected in dry, clean and sterile polythene bags and transported to the laboratory for microbiological analysis within one hour of collection or refrigerated at $4^{\circ} \mathrm{C}$ till further analysis. These samples were then processed no later than 24 hours after collection. These samples were then swabbed with sterile cotton swabs and inoculated into the Brain Heart Infusion broth (BHI) and then incubated overnight at $37^{\circ} \mathrm{C}$. After $18-24 \mathrm{hrs}$, the swabs from BHI broth were streaked onto the different media plates like Brain Heart Infusion Agar (BHI), PALCAM Selective Agar (PSA) for isolation of Listeria spp.

\section{Identification of bacterial isolates}

The bacterial colonies were isolated after incubation. These colonies were subjected to Gram's staining for identification and requisite biochemical tests were carried out to further confirm the presence of the pathogen. The final confirmation of the organism was done by using molecular techniques like PCR.

\section{Biochemical characterization}

L.monocytogenes suspected colonies were subjected to various biochemical tests like the Catalase test and L.monocytogenes identification kit (HIMEDIA) for Voges Proskauer, Catalase, Esculin hydrolysis, Nitrate reduction, Methyl red and various carbohydrate utilization tests including Glucose, Mannitol, Sucrose, Lactose, Rhamnose, Xylose, and a-Methyl-D mannoside tests. 


\section{Molecular characterization}

The DNA was extracted from suspected colonies and tissues using Himedia DNA extraction kits. The extracted DNA was subjected to PCR for the detection of bacterial DNA in the samples using published primers and probes.

\section{Polymerase Chain Reaction (PCR)}

The DNA extracted was subjected to polymerase chain reaction using specific primers for L.monocytogenes. The $25 \mu \mathrm{l}$ reaction mixture for PCR was prepared that consisted of $13 \mu \mathrm{l}$ Mastermix (Promega), $1 \mu \mathrm{l}$ each of $20 \mathrm{pmol} / \mu \mathrm{l}$ Forward primer and Reverse primer, $5 \mu \mathrm{l}$ of DNA template and 5 $\mu 1$ of Nuclease free water. PCR was performed on $\mathrm{C} 1000$ touch thermocycler (Bio-Rad, USA) with the following conditions; an initial denaturation at $95^{\circ} \mathrm{C}$ for 5 minutes and later 35 cycles of denaturation at $94^{\circ} \mathrm{C}$ for 30 seconds, annealing at $55^{\circ} \mathrm{C}$ for 1 minute and extension at $72^{\circ} \mathrm{C}$ for 1 minute. The final extension followed at $72^{\circ} \mathrm{C}$ for 10 minutes. The PCR products were run on $1.5 \%$ agarose along with 50 bp DNA molecular weight marker (New England Biolabs, USA) at $5 \mathrm{~V} / \mathrm{cm}$ and visualized using a gel documentation system (AlphaImager, Alpha Innotech, USA).

\section{Results and Discussion}

Out of total 100 meat samples, 80 raw and 20 frozen meat product samples examined for the presence of bacterial pathogens. The Listeria monocytogenes was isolated from total 02 fresh samples i.e. 02\% (Table 1) which were Catalase positive and later confirmed by PCR detection at $64 \mathrm{bp}$. The findings of the present study are in line with the observation of Kalorey et al., (2005) who reported using a conventional culture and biochemical tests, a total of $08(8.5 \%)$ of all investigated samples being Listeria positive. The samples following the standard protocol were streaked on PALCAM Selective Agar (PSA) (Chapman, 1945) for selective culture of $L$. monocytogenes and black colonies surrounded with black zone in the media were obtained. The isolation results for $L$. monocytogenes are in concurrence with the findings of other workers.Franco et al., (1995) used conventional culture methods and techniques to report the presence of Listeria spp. in chicken drumsticks, wings, breasts, and livers taken from a poultry processing plant to be $96 \%$ positive. Mahmood et al., (2003) in a study performed on 320 samples of raw and frozen poultry meat and meat products found the prevalence of Listeria spp. to be ranging from 10 to $37.5 \%$. Kalorey et al., (2005) applied CAMP test and other culture characteristics to report $8.5 \%$ isolation of Listeria spp. out of the 94 samples examined. Reiter et al., (2005) in a study used the automated mini-VIDAS system (Enzyme Linked Fluorescent Assay) to detect the presence of L. monocytogenes on the raw and frozen meat samples. L. monocytogenes were found in $35.6 \%$ of the 645 analyzed samples, respectively. Chemaly et al., (2008) undertook a study involving two hundred laying-hen flocks and reported an estimated prevalence of $15.5 \%$ in laying-hen flocks. They also used the simple isolation techniques for the confirmation of the prevalence. Alsheikh et al., (2013) employed biochemical tests as per conventional International Organization for Standardization methods for studying the prevalence of Listeria spp. on 250 broiler chickens and ready to eat meat products. L. monocytogenes was isolated to the tune of $13.6 \%$ besides other Listeria spp. viz. $20.8 \%$ for L. ivanovi and to minimal levels of $0.8 \%$ for L. seeligeri. Dahshan et al., (2016) collected a total of 200 poultry farm samples and species wise isolated the organism using standard isolation methods wherein various species of listeria 
were isolated and of which L. monocytogenes accounted for meager 1\%. Maung et al., (2019) collected a total of 85 and 50 chicken meat samples, including different body parts from different supermarkets in Fukuoka (Japan) in 2012 and 2017, respectively. Detection, isolation, identification, and characterization of L. monocytogenes were performed according to the conventional methods. Forty-five among 85 samples (53\%) were positive for L. monocytogenes in 2012, while 12 among 50 samples in 2017 (24\%) tested positive.

Table.1 Comparison of detection of Listeria monocytogenes in meat samples using various techniques

\begin{tabular}{|l|c|c|}
\hline \multirow{2}{*}{ Techniques } & \multicolumn{2}{|c|}{ Total fresh meat samples (80) } \\
\cline { 2 - 3 } & Listeria spp. & \% \\
\hline Isolation & 02 & 2.5 \\
\hline PCR & 02 & 2.5 \\
\hline Total & 02 & $\mathbf{2 . 5}$ \\
\hline
\end{tabular}

Fig.1 Growth of L. monocytogenes on Palcam Selective Agar (PSA) medium with colonies appearing black with a black zone in surrounding medium

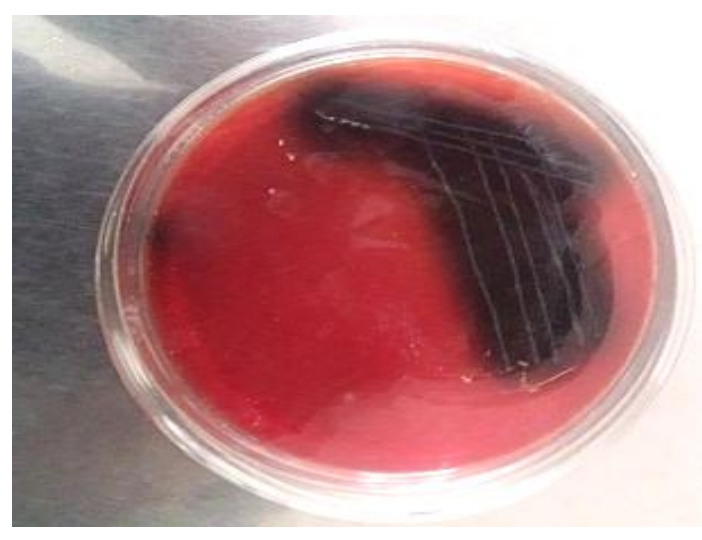

Fig.2 Listeria spp. from culture seen as numerous Gram positive rods. Gram's stain. 100X

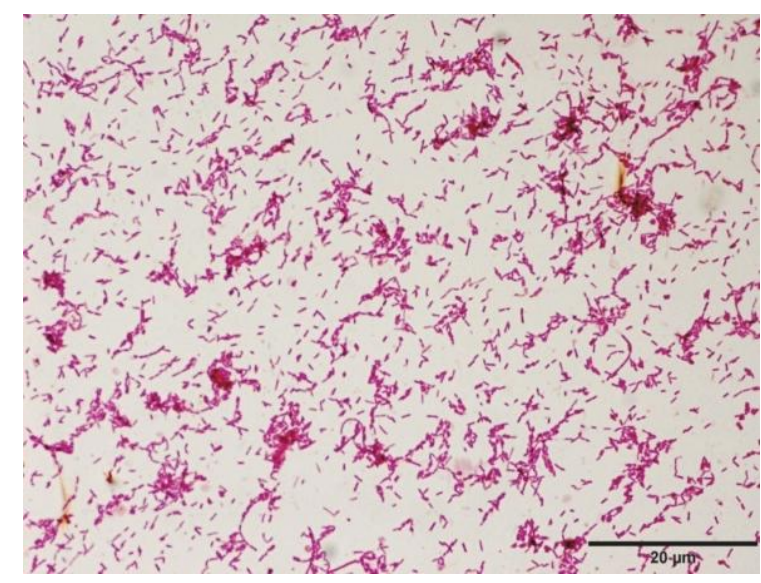


Fig.3 Catalase test for L. monocytogenes: Catalase test showing positive frothy effervescence

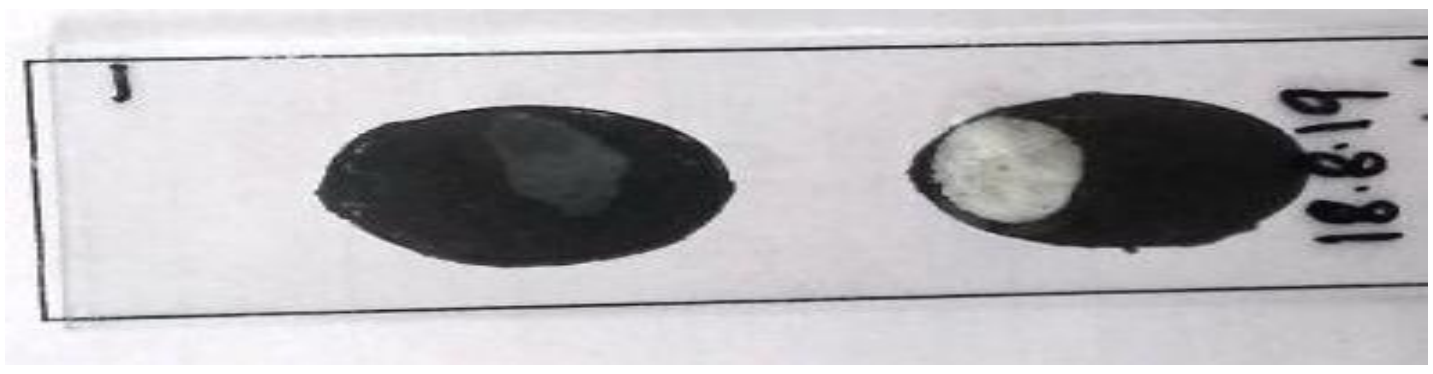

Fig.4 Biochemical test for Listeria spp. using Listeria identification kit by HiMedia

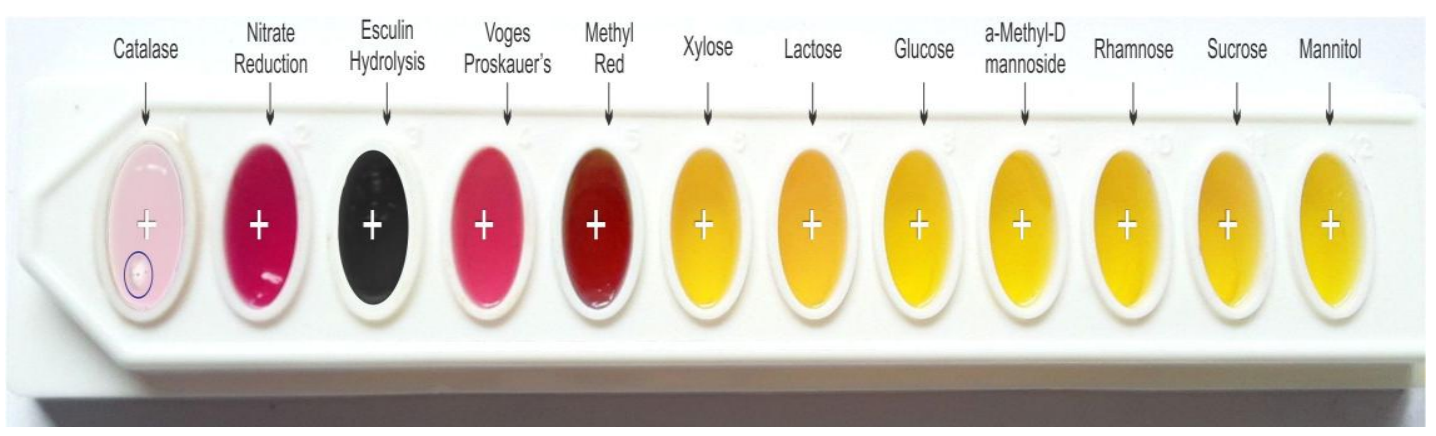

Fig.5 Molecular identification of L. monocytogenes at 64 bp targeting $h l y$-A gene. M=50bp DNA ladder; L1 to L2= test samples showing distinct bands at 64bp; PTC= Positive template control; NTC $=$ Negative template control

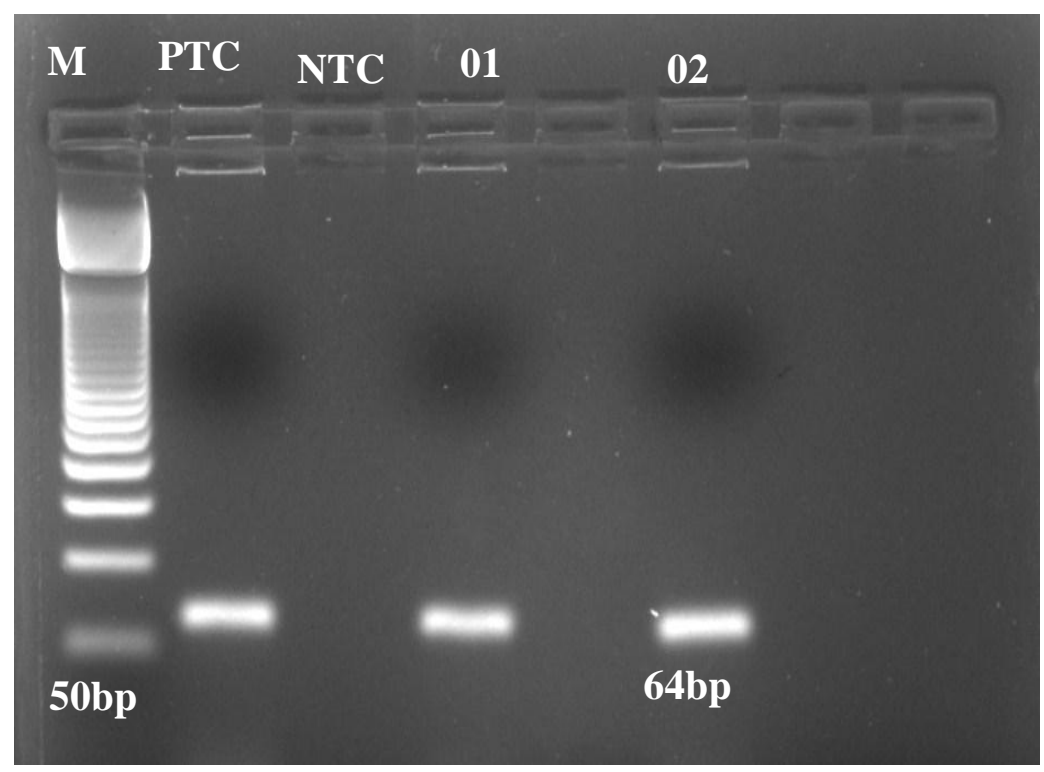

The colonies picked from PALCAM Selective Agar (PSA) were subjected to Catalase test which showed positive reactivity (Foster, 1996).The L. monocytogenes organisms exhibited greyish/black colonies with peripheral black zones when grown on Oxford and PALCAM agar, a selective media for their growth (Fig.1). Furthermore, the 
Gram's staining performed on isolated colonies revealed numerous Gram positive rods(Fig.2).Catalase test for the bacteria showed frothy effervescence when positive culture of the bacteria was inoculated with $\mathrm{H}_{2} \mathrm{O}_{2}$ (Fig.3).Furthermore, biochemical test kit (Himedia) was used in the study for confirming the presence of Listeria spp.(Fig.4) with the help of 12 tests for identification of $S$. aureus namely Catalase, Nitrate Reduction, Esculin hydrolysis, Voges Proskauer's, Methyl red, Xylose, Lactose, Glucose, a-Methyl-D mannoside, Rhamnose, Sucrose, Mannitol. The results from the kit confirmed the presence of Listeria spp. The findings of the present study are in consonance with the observations of Ennaji et al., (2008) in a study conducted at Casablanca, Morocco on the chicken meat samples (74) sold in supermarkets. In their study they found only 1 positive sample for Listeria monocytogenes with overall prevalence of $1.3 \%$. Vasu et al., (2014) who used biochemical tests on a total of 100 surface swabs (table tops and knives) from meat processing facilities and retail markets in Kerala and found 3\% prevalence of Listeria spp.

Ahmed et al., (2017) used common biochemical tests to detect the Listeria organism in chicken meat and reported that 04 samples out of 50 samples were positive for the presence of L. monocytogenes. In another similar finding Kureljušić et al., (2017) conducted a six month study in republic of Serbia by using standard biochemical tests to report 3\% prevalence of Listeria spp. in poultry meat samples.Soleimani et al., (2019) by employing preferential selective culture media and various biochemical tests isolated Listeria monocytogenes which were later attested by PCR assay. Of the 247 samples $27 \%$ samples revealed L. monocytogenes besides other.
Standard PCR (Fig.5) was run to establish the presence of the pathogen and check the efficacy and priming conditions related to the primers and master mix used in the study. PCR was done to confirm the presence of Listeria spp. by targeting $h l y-A$ gene at 64bp using published primers (Lazaro et al., 2004).

Osaili et al., (2011) on a study done on 280 samples found $50 \%$ of samples contaminated with Listeria spp. of which L. monocytogenes accounted for $18.2 \%$ based on the routine conventional methods and supported by Polymerase chain reaction (PCR). Zeinali et $a l$. , (2017) examined the chicken meat sold at different supermarkets by collecting 200 random fresh chicken carcasses and subjected them to isolation of Listeria spp. $40 \%$ of the samples did reveal Listeria spp. of which $18 \%$ was attributed to Listeria monocytogenes. This was further evidenced by use of multiplex PCR assay.

In conclusion the poultry meat sector aims at providing long shelf life ready to eat and other meat products, which are safe for human consumption but various biological hazards have been associated with poultry meat production and consumption. Listeriaspp. has been ranked as one of the high risk pathogenin contaminated meat due to the severity of the illnessit causes and its impact on human health. The results of this study have confirmed that contamination of $L$. monocytogenes occurs due to insufficient hygiene and that there may be a serious risk in raw poultry meat for consumer health in India, because of the detection of $L$. monocytogenes in the samples. Therefore, the combination of high throughput detection methods with highly selective cultural methods and rapid, reliable and sensitive molecular techniques like PCR will be needed to identify the sources of meat contaminants and their dynamics during processing and storage. 


\section{Acknowledgment}

We express our sincere thanks to the Science and Engineering Research Board (SERB), Ministry of Food Processing Industry, Government of India, for providing sufficient funds to carry out this research work in a time-bound manner.

\section{References}

Ahmed, S S T S., Tayeb, B H., Ameen,A.M, Merza, S.M and Sharif, Y. H. M. 2017. Isolation and Molecular Detection of Listeria monocytogenes in Minced Meat, Frozen Chicken and Cheese in Duhok Province, Kurdistan Region of Iraq. Journal of Food: Microbiology, Safety and Hygiene 2:118.

Alsheikh, A. D. I., Mohammed, G. E and Abdalla, M.A. 2013. Isolation and Identification of Listeria monocytogenes from retail broiler Chicken ready to eat meat products in Sudan. International Journal of Animal and Veterinary Advances, 5: 9-14.

Chapman, GH. 1945. The significance of sodium chloride in studies of staphylococci. Journal of Bacteriology 50(2): 201.

Chemaly, M., Toquin, M. T., Notre,Le.Y.,Fravalo, $\quad$ P. 2008. Prevalence of Listeria monocytogenes in poultry production in France. Journal of Food Protection 71: 1996-2000.

Dahshan, H., Merwad, A and Mohamed, T. S. 2016. Listeria species in broiler poultry farms: Potential public health hazards. Journal of Microbiology and Biotechnology 26(9):1551-56.

Ennaji, H., Timinouni, M., Ennaji, M.M., Hassar, M., Cohen, N. 2008. Characterization and antibiotic susceptibility of Listeria monocytogenes isolated from poultry and red meat in Morocco. Infection and Drug Resistance 1:45-50.

Franco, C. M., Quinto, E. J., Fente, C., Rodriguez-Otero, J. L., Dominguez, L and Cepeda, A. 1995. Determination of the principal sources of Listeria species contamination in poultry meat and a poultry processing plant.Journal of Food Protection 58: 1320-25.

Kalorey, D. R., Barbuddhe, S.B., Kurkure, N. $\mathrm{V}$ and Gunjal, P.S. 2005.Prevalence of Listeria monocytogenes in poultry meat in Vidharba region of India. In: Proceedings of the 17th European Symposium on the Quality of Poultry Meat. Doorwerth, Netherlands.

Kureljušić, J., Rokvić, N., Jezdimirović, N., Kureljušić, B., Pisinov, B and Karabasil, N. 2017.Isolation and detection of Listeria monocytogenes in poultry meat by standard culture methods and PCR. In: IOP Conference Series: Earth and Environmental Science 85(1):012-069.

Lazaro, D. R., Hernandez, M., Scortti, M., Esteve, T., Boland, J.A.V and Pla, M. 2004. Quantitative detection of Listeria monocytogenes and Listeria innocua by real-time PCR: assessment of hly, iap and lin02483 targets and amplifluor technology. Applied and Environmental Microbiology70(3): 1366-77.

Luna, L. G. 1968. Manual of Histologic Staining Methods of the Armed Forces Institute of Pathology, $\quad 3^{\text {rd }}$ Edn. McGraw-Hill, New York, p. 259.

Mahmood, M. S., Ahmed, A. N and Hussain, I. 2003. Prevalence of Listeria monocytogenes in poultry meat, poultry meat products and other related in animates at Faisalabad. Pakistan Journal of Nutrition2(6): 346-49.

Maung, A.T., Mohammadi, T.N., Nakashima, S., Liu, P., Masuda, Y and Honjoh, K.I. 2019. Antimicrobial resistance 
profiles of Listeria monocytogenes isolated from chicken meat in Fukuoka, Japan. International Journal of Food Microbiology, 304:49-57.

Osaili, T., Alaboudi, A and Nesiar, E. 2011. Prevalence of Listeria spp. and antibiotic susceptibility of Listeria monocytogenes isolated from raw chicken and ready-to-eat chicken products in Jordan. Food Control22: 586-90.

Reiter, M.G.R., Bueno, C. M. M., Lopez, C and Jordano, R. 2005. Occurrence of Campylobacter and Listeria monocytogenes in a poultry processing plant. Journal of Food Protection68: 1903-06.

Soleimani, M., Khalili, S.E and Hamidian, N., Heydari, A and Mohajeri, F.A. 2019.
Prevalence and Antibiotic Resistance of Listeria monocytogenes in chicken meat retailers in Yazd, Iran. Journal of Environmental Health and Sustainable Development4(4): 895-902.

Vasu, R. K., Sunil, B., Latha, C., Vrinda, M. $\mathrm{K}$ and Kumar, A. 2014. Prevalence of Listeria species in meat processing environments. International Journal of Current Microbiology and Applied Science 3(2): 542-46.

Zeinali, T., Jamshidi, A., Bassami, M., and Rad, M. 2017. Isolation and identification of Listeria spp. in chicken carcasses marketed in Northeast of Iran. International Food Research Journal24(2): 881-87.

\section{How to cite this article:}

Nishchal Dutta, H. S. Banga, Sidhartha Deshmukh and Geeta Devi Leishangthem 2020. Prevalence, Detection and Identification of Listeria monocytogenes in Retail Chicken Meat in Ludhiana, India by Employing conventional Isolation Techniques and Molecular Polymerase Chain Reaction (PCR) Assay. Int.J.Curr.Microbiol.App.Sci. 9(07): 1510-1517. doi: https://doi.org/10.20546/ijcmas.2020.907.174 